\title{
PROJECT OF THE STRENGTHENING OF A WATER TANK CARRIER SYSTEM WITH CARBON FIBER MATERIAL ${ }^{*}$
}

\author{
Mehmet Fatih ALTAN', Muhammed AYDOĞAN² \\ ${ }^{1}$ Prof., Department of Civil Engineering, Istanbul Aydin University, Istanbul, Turkey, \\ mehmetaltan@aydin.edu.tr, ORCID:0000-0003-0961-0115 \\ ${ }^{2}$ Department of Civil Engineering, Istanbul Aydin University, Istanbul, Turkey, \\ mhmmdaydogan@gmail.com,ORCID:0000-0002-8804-6577
}

\begin{abstract}
Elevated water tanks with reinforced concrete carrier systems are extremely important structures for public service or industrial use, and therefore they should be kept in a usable condition after an earthquake. The design and construction methods of these structures are affected by current construction practices, physical properties of the material and climatic conditions. Structural system damages are inevitable due to reasons such as improper designs, wrong analysis, lack of seismic wave resistant design, faulty geological preferences. In this study, the reinforced concrete carrier system of a sample water tank was examined in both cases, both in its current form and reinforced with FRP, using the SAP2000 program. By discussing the advantages of using FRP in these structures, it was suggested that it could be preferred primarily for reinforcement.
\end{abstract}

Keywords: Pushover Analysis, Reinforcement, Seismic Performance, Vibration Forces, Elevated Water Tanks.

\section{INTRODUCTION}

Elevated water tanks with reinforced concrete carrier systems are extremely important structures for public service or industrial use, and therefore they should be kept in a usable condition after an earthquake. The design and construction methods of these structures are affected by current construction practices, physical properties of the material and climatic conditions. Structural system damages are inevitable due to reasons such as improper designs, wrong analysis, lack of seismic wave resistant design, faulty geological preferences. Water tank design parameters include selecting the overall design of the tank, building materials and coatings. The design depends on the location of the tanks, different approaches are used for aboveground or underground water tanks [1]. Tanks can be made of RC or steel. Raised tanks are usually raised above ground level

\footnotetext{
${ }^{1 *}$ Received: 08.01.2021 - Accepted: 14.01.2021

DOI: 10.17932/EJEAS.2021.024/ejeas_v01i1003
} 
using columns and beams. Retrofitting is a method applied to increase the strength of the existing structure and also increases the strength of the newly constructed structures due to the error in the design and construction errors. If we list the methods of retrofitting. Over slabbing, sprayed concrete with additional reinforcement, steel plate bonding, external prestressing, concrete jacketing, steel jacketing and FRP wrapping $[2,3]$.

\section{MATERIALS AND METHODS}

Housner conducted the first research to address the seismic response behavior of both underground and high water reservoirs exposed to earthquake lateral loads. Housner proposed a formulation to model the dynamic response of water inside tanks that are still widely used in engineering practice. According to Housner's proposed formulation, the hydrodynamic response is divided into two components of impulsive and convective vibration [4,5]. It is assumed that the impulsive vibration mode is attached to the tank wall (rigid connection). Convective motion, on the other hand, is the oscillation of the water surface, which has a longer vibration period, modeled as a collective mass attached to the wall using springs [6].

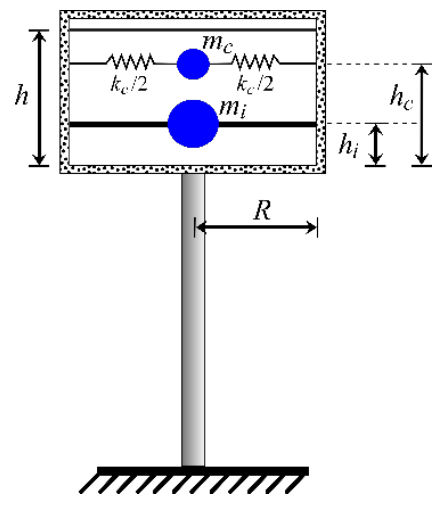

Figure 1: Mechanical model equivalent to the raised water tank

The equations for the Housner (Epstein, 1976) approximations for hydrodynamic pressure are set below [7].

$$
\begin{aligned}
& \omega^{2}=\frac{g}{R} 1.84 \tanh \left(1.84 \frac{h}{R}\right) \\
& h_{i}=\frac{3}{8} h \\
& k_{c}=m_{c} \frac{g}{R} 1.84 \tanh \left(1.84 \frac{h}{R}\right)
\end{aligned}
$$


$m_{c}=m_{w} \cdot 0.318 \frac{R}{h} \tanh \left(1.84 \frac{h}{R}\right)$

$m_{i}=m_{w} \frac{\tanh \left(1.74 \frac{R}{h}\right)}{1.74 \frac{R}{h}}$

$h_{c}=\left(1-\frac{\cosh \left(1.84 \frac{h}{R}\right)-1}{1.84 \frac{h}{R} \sinh \left(1.84 \frac{h}{R}\right)}\right) h$

Where, $w$ structural frequency, $k_{c}$ stiffness of convective mass springs, $m_{c}$ convective masses, $m_{i}$ impulsive mass, $h_{c}$ height of convective masses, $h_{i}$ height of the impulsive mass, $m_{w}$ total mass and $g$ ground acceleration [8].

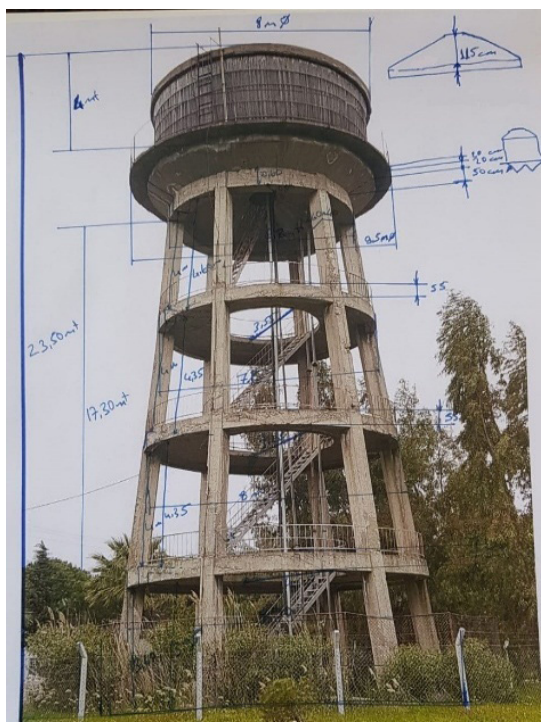

Figure 2: Sample water tank with RC carrier system

The SI international measurement unit system $(\mathrm{kN}, \mathrm{m})$ was used both in design, calculations and drawings. 
Table 1: SI international units of measure

\begin{tabular}{cc}
\hline Physical size & Unit of \\
\hline Length & $\mathrm{m}$ \\
Loads & $\mathrm{kN}$ \\
Weight & $\mathrm{kN}$ \\
Mass & $\mathrm{Kn} \cdot \mathrm{sn}^{2} / \mathrm{m}$ \\
Momentum & $\mathrm{kN} \cdot \mathrm{m}$ \\
Stress & $\mathrm{kN} / \mathrm{m}^{2}$ \\
\hline
\end{tabular}

For the structural design of the structure, SAP2000 Ver 14.2.4 computer aided design and analysis program, capable of performing finite element analysis, was used. The dead load will include the weights of all fixed parts of the structures and their additions. The following assumptions have been made for all weight calculations.

- Roof cover volume unit weight, $\gamma=0.25 \mathrm{kN} / \mathrm{m}^{2}$

- Volume unit weight of reinforced concrete, $\gamma=25.0 \mathrm{kN} / \mathrm{m}^{3}$

- Volume unit weight of concrete without reinforcement, $\gamma=25.0 \mathrm{kN} / \mathrm{m}^{3}$

- $\quad \mathrm{G}$ dead $=$ dead load

- $\mathrm{WG}=$ water weight

- $\quad$ live $=3 \mathrm{kN} / \mathrm{m}^{2}$

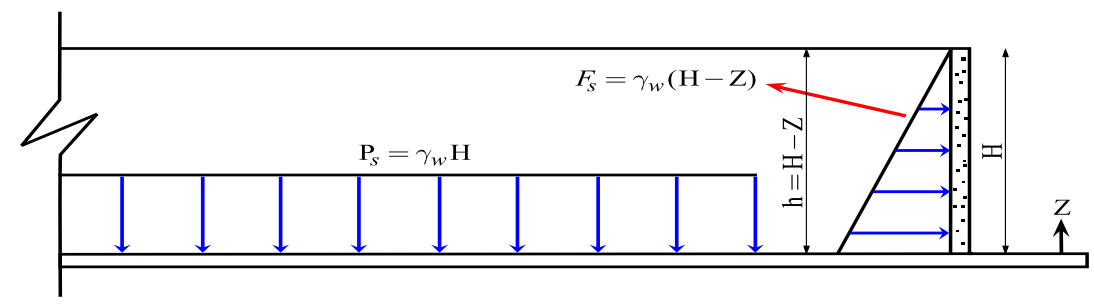

Figure 3: Hydrostatic pressure (a)

If we take $\mathrm{F}_{\mathrm{s}}=\gamma_{\mathrm{w}}(\mathrm{H}-\mathrm{Z})=1000(4-\mathrm{Z})$ and $\mathrm{Z}=0$

$\mathrm{F}_{\mathrm{s}}=4000 \mathrm{~kg} / \mathrm{m}^{2}=40 \mathrm{kN} / \mathrm{m}^{2}$ is found.
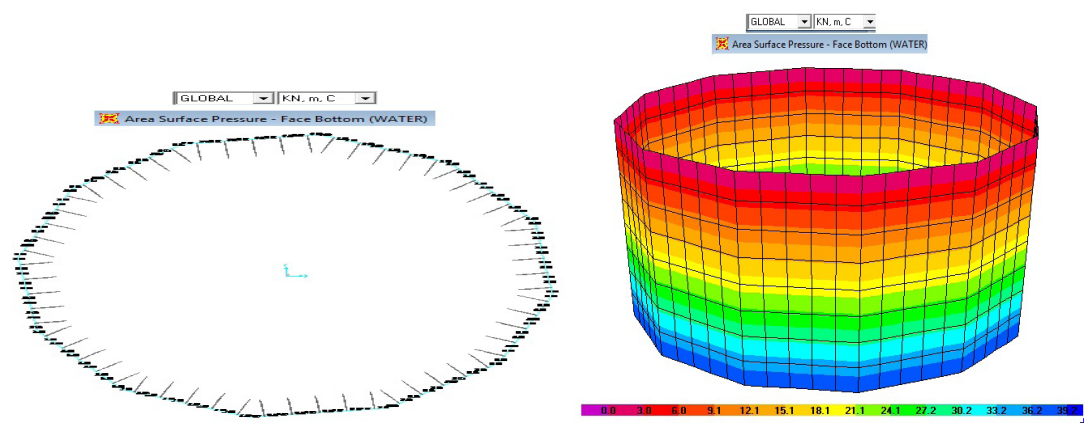

Figure 4: Hydrostatic pressure (b) 
Table 2: Effective ground acceleration coefficient $\left(A_{0}\right)$

\begin{tabular}{cc}
\hline Earthquake Zone & $\boldsymbol{A}_{\mathbf{0}}$ \\
\hline 1 & 0.40 \\
2 & 0.30 \\
3 & 0.20 \\
4 & 0.10 \\
\hline
\end{tabular}

The effective ground acceleration coefficient for the earthquake load is taken as $A_{\mathrm{o}}=$ 0.4 , building importance factor, $I=1$ and soil group $=\mathrm{C}$ (Soil Investigation Report). The Spectrum coefficient is calculated from the following equations.

$$
S(T)= \begin{cases}1+1.5 \frac{T}{T_{A}} & , 0 \leq T \leq T_{A} \\ 2.5 & , T_{A}<T \leq T_{B} \\ 2.5\left(\frac{T_{B}}{T}\right)^{0.8} & , T_{B}<T\end{cases}
$$

The following defined reduced acceleration spectrum is used in Sap2000.

$$
S_{R}\left(T_{n}\right)=\frac{S\left(T_{n}\right)}{R_{a}\left(T_{n}\right)}
$$

Calculation of the storey masses was made by taking $n=0.3$ according to the following equations.

$$
\begin{aligned}
& W=\sum_{i=1}^{N} w_{i} \\
& w_{i}=g_{i}+n q_{i}
\end{aligned}
$$

Table 3: Spectrum characteristic periods $\left(T_{A}, T_{B}\right)$

\begin{tabular}{ccc}
\hline Local ground class & $T_{A}(\mathrm{sec})$ & $T_{B}(\mathrm{sec})$ \\
\hline Z1 & 0.10 & 0.30 \\
Z2 & 0.15 & 0.40 \\
Z3 & 0.15 & 0.60 \\
Z4 & 0.20 & 0.90 \\
\hline
\end{tabular}

For the internal forces found, the section will be increased by taking $\beta=0.9$, and if $V_{\mathrm{tB}}<$ $\beta . V_{\mathrm{t}}$ for the predicted earthquake, all internal force and displacement magnitudes found according to the mode combination method will be increased according to equation 11 .

$$
B_{\mathrm{D}}=\frac{\hat{\mathrm{a}} V_{t}}{V_{t B}} B_{\mathrm{B}}
$$



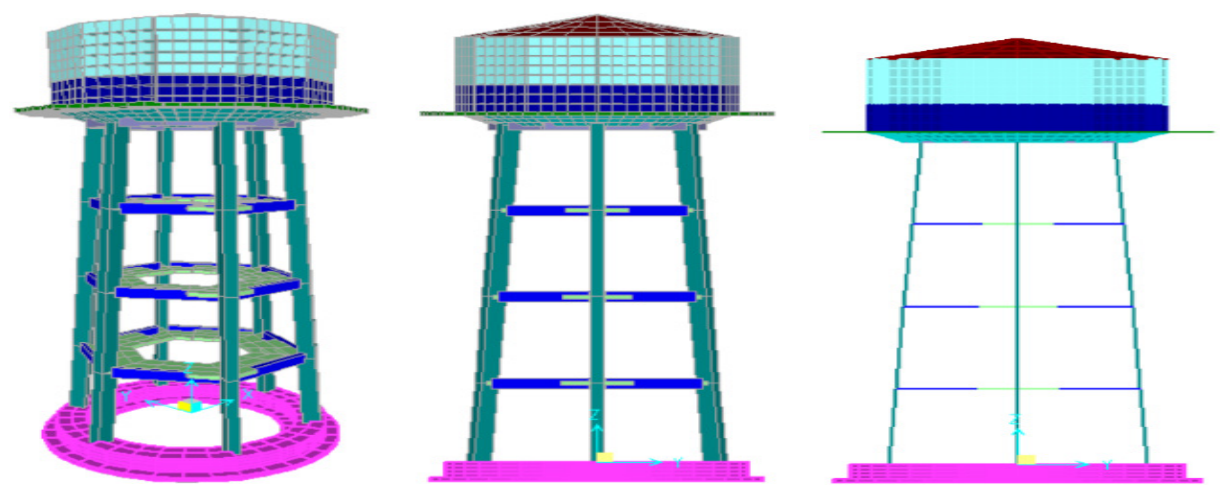

Figure 5: Computer model of the building

Where $V_{\mathrm{tB}}$ is the building total load and $V_{\mathrm{t}}$ is the building total earthquake load. The formulas used for the equivalent earthquake load value to be used for the above calculation;

$$
\begin{aligned}
& A(T)=A_{0} \cdot I \cdot S(T) \\
& S_{a e}(T)=A(T) \cdot g \\
& V_{t}=\frac{W \cdot A\left(T_{1}\right)}{R_{a}\left(T_{1}\right)} \geq 0.10 \cdot A_{0} \cdot I \cdot W \\
& T_{1}=2 \pi\left(\frac{\sum_{i=1}^{N} m_{i} \cdot d_{f i}^{2}}{\sum_{i=1}^{N} F_{f i} \cdot d_{f i}}\right)^{\frac{1}{2}}
\end{aligned}
$$




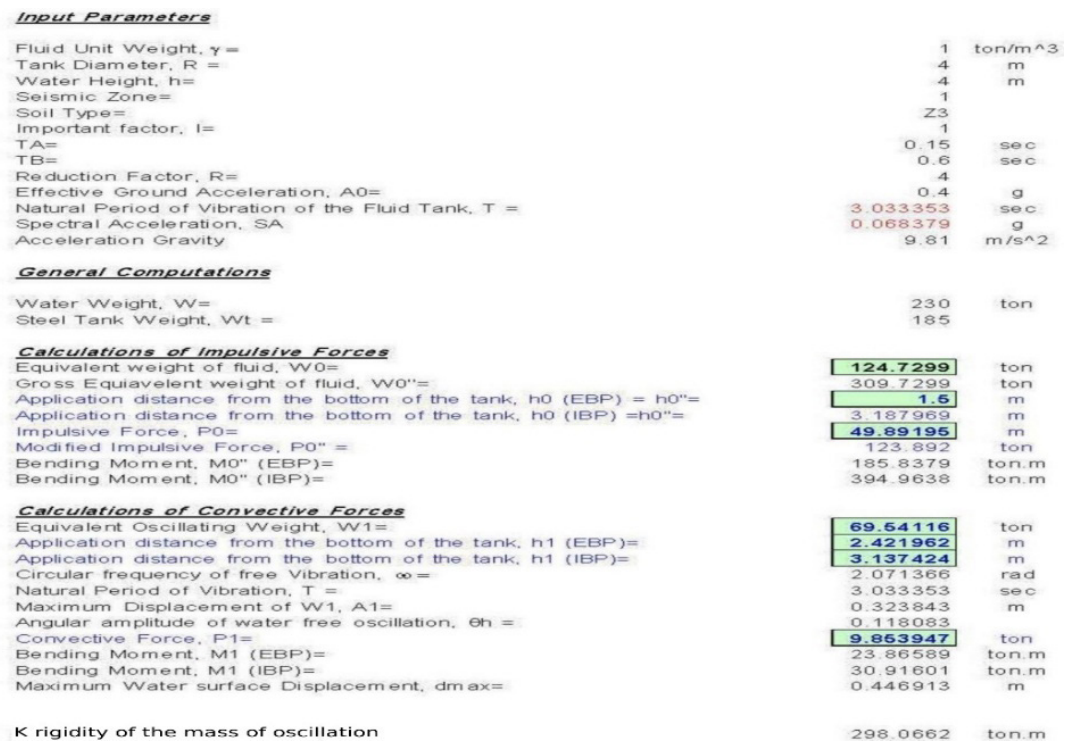

Figure 6: Hydrodynamic forces in a cylindrical tank $(\mathrm{h}<1.5 \mathrm{R})$

\section{REINFORCEMENT OF THE WATER TANK USING FRP}

The displacement limit for the non-reinforced model is $=:(\operatorname{disp} / \mathrm{h})<0.025$, disp $(\max )=$ $0.025 \times 18.35 \times 100 / 4.5=10.1 \mathrm{~cm}$ and the displacement in the model is $=17.80 \mathrm{~cm}$. If we take the time period $=1.26$;
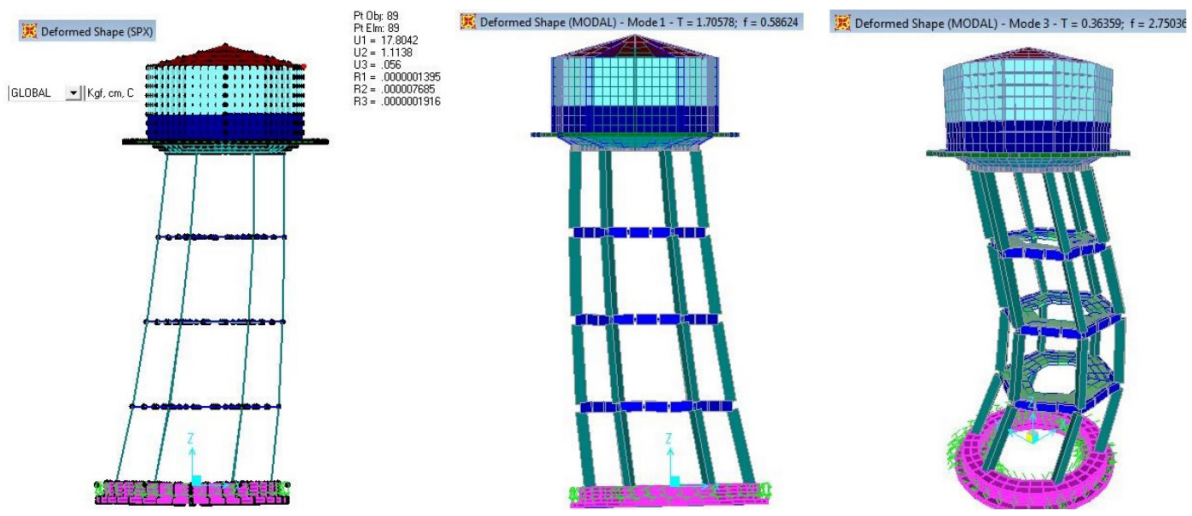

Figure 7: Deformed shape

All of the columns have $2 \emptyset 14$ iron in $4 \emptyset 22$ cores on short corners and stirrups are positioned $\emptyset 8 / 20 \mathrm{~cm}$ apart. For all the beams, there are $2 \varnothing 12$ piles at the top and $4 \varnothing 12$ reinforcement at the bottom. In this model, the concrete class has been entered as $f_{c}=10$ Mpa. 

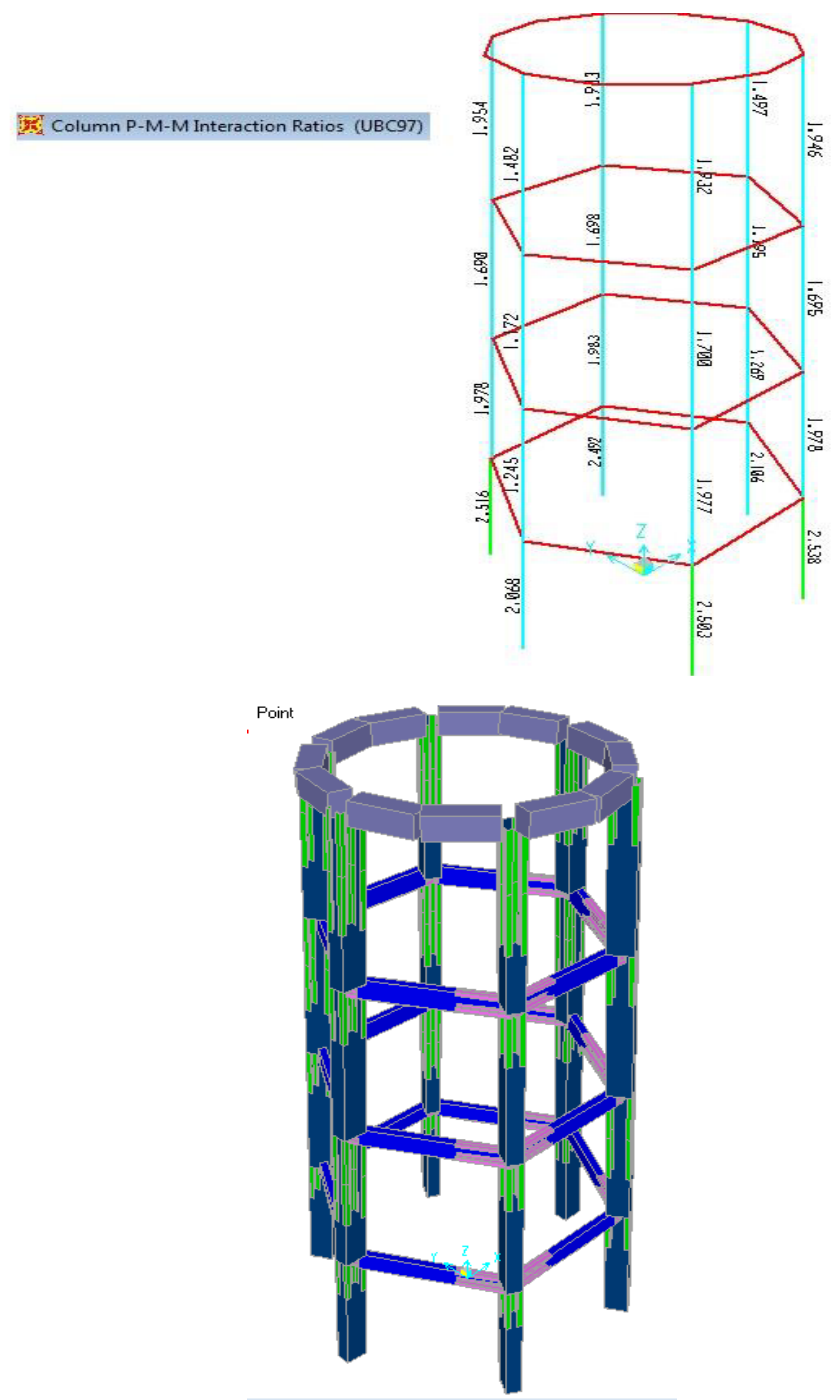

(a)

(b)

Figure 8: (a) Column and beam design (not reinforced) (b) Bracing made in beams and columns

For the model reinforced with FRP, the braces are 4 pieces $(12 \times 12 \times 1)$ and the brace area is: $24 \mathrm{x} 4=96 \mathrm{~cm}^{2}$. 


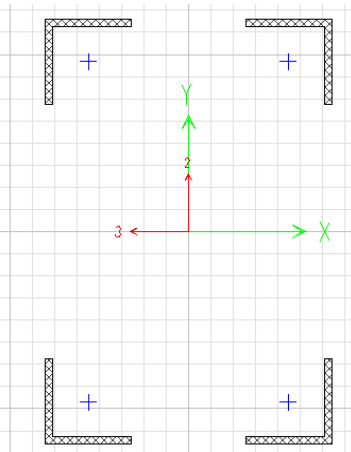

Figure 9: Column section with FRP bracing

After these brackets are made, we use the section in Figure 10 (b) instead of the column section.

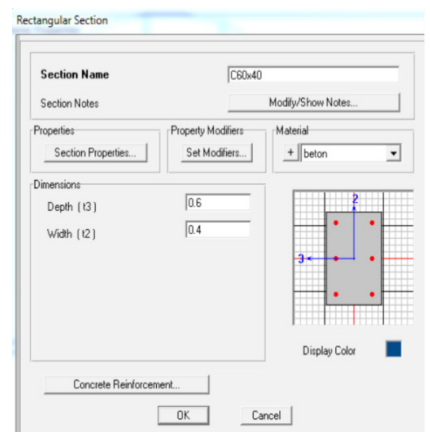

(a)

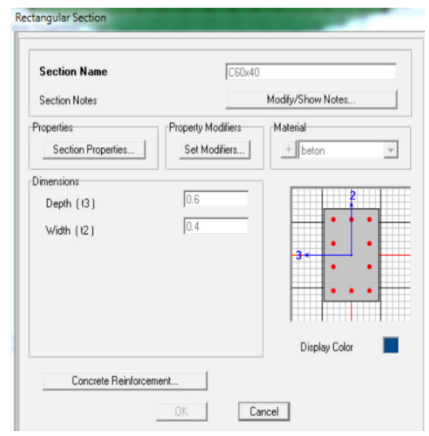

(b)

Figure 10: (a) Non-reinforced column section (b) Reinforced column section

Assuming that it increases the axial strength of the column by $100 \%$, the concrete class has been entered as $\mathrm{f}_{\mathrm{c}}=20 \mathrm{Mpa}$.

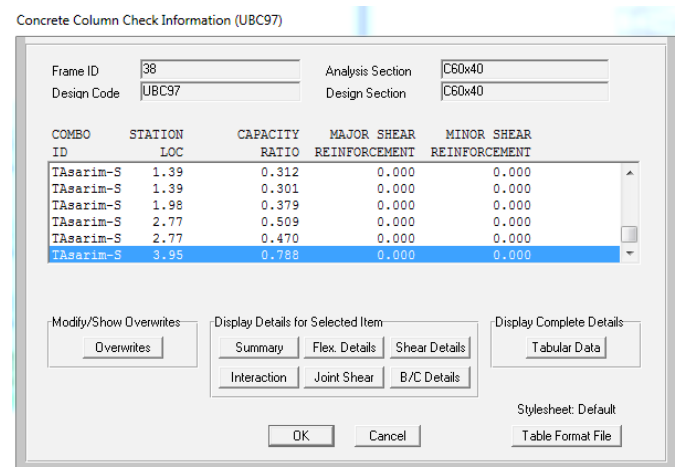

Figure 11: Column check information 

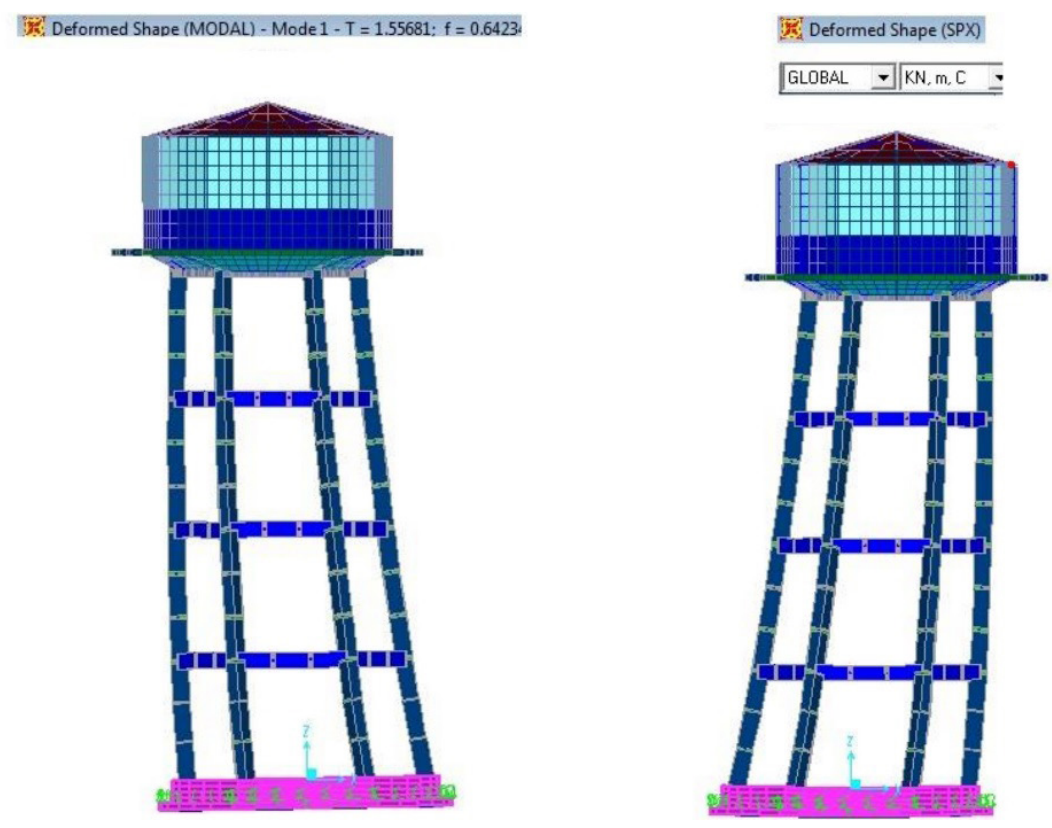

Figure 12: Time period $=1.56$ seconds $($ period dropped $20 \%)$

The displacement limit $=:(\operatorname{disp} / \mathrm{h}) \times \mathrm{cd}<0.025$ and $\operatorname{disp}(\max )=0.025 \times 18.35 \times 100 /$ $4.5=10.2 \mathrm{~cm}>8.2 \mathrm{~cm}$.

\section{id: Column P-M-M Interaction Ratios (UBC97)}

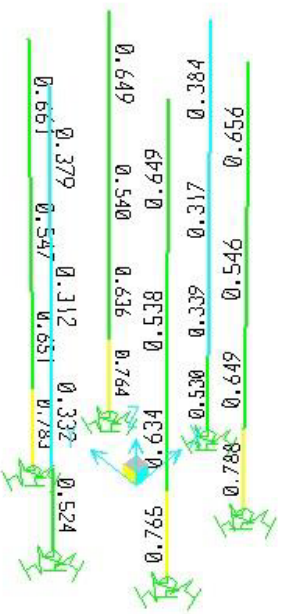

Figure 13: Column P-M-M interaction ratios 
$\mathrm{k}_{\mathrm{s}}=10000 \mathrm{kN} / \mathrm{m}^{3}$ and ground safety tension $=100 \mathrm{kN} / \mathrm{m}^{2}$.

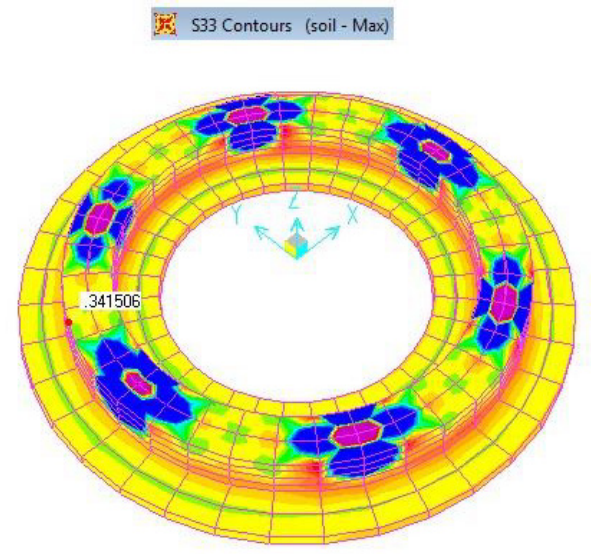

Figure 14: Foundation stresses $(0.75$ Dead +0.75 Q Live $+0.75 \mathrm{SPX})$ were taken.

\section{CONCLUSION AND SUGGESTIONS}

FRP has an elastic behavior up to failure, unlike steel which exerts a constant wrapping pressure after application, and therefore applies the wrapping action differently than steel on concrete specimens under axial load. The advantages of using FRP to strengthen the carrier systems of water tanks can be listed as follows.

- It is resistant to corrosion,

- High strength / weight ratio,

- Shorter assembly time and cost,

- It is not conductive and metallic,

- Low maintenance requirements,

Fire resistance, which is an important disadvantage in the use of FRP, is not valid in water tanks. The possibility of fire in a building with risks from heating systems or full of flammable materials is not present in the water tank. In addition, we can talk about an extra advantage since no flammable material is stored in this type of tank. The possibility of leaks in the water tanks to cause corrosion in the conveyor system due to wear or insufficient maintenance is seriously reduced by the use of FRP. Advantages of using FRP over steel reinforcement include linear elastic behavior on failure, no yield, higher ultimate strength, and lower strain on failure. As a result, the use of FRP in water tanks is extremely important due to its increased load capacity and increased deformation capability. 


\section{REFERENCES}

[1] Biradar G., Prakash C. H., Suresh D., Kumar S. K. S. (2016). Structural Strengthening of Reinforced Column.

[2] Kapadia I., Dholiya N., Patel P., Patel N. (2017). Parametric Study of Rcc Staging (Support Structure) For Overhead Water Tanks As Per 1S:811682-1985 and IS:3370.

[3] Soroushnia S., Tafreshi T., Omidinasab F., Beheshtian N., Soroushnia S. (2011). Seismic Performance of RC Elevated Water Tanks with Frame Staging and Exhibition Damage Pattern.

[4] Thalapathy M., Vijaisarathi R. P., Sudhakar P., Sridharan V., Satheesh V. S. (2016). Analysis and Economical Design of Water Tanks.

[5] Motavalli M. (2019). Column Confinement - Empa.

[6] ISIS Educational Module 4, An Introduction to FRP Strengthening of Concrete Structures, 2010.

[7] Livaoğlu R., Doğangün A. (2006). Simplified seismic analysis procedures for elevated tanks considering fluid-structure-soil interaction.

[8] Ghateh R. (2006). Nonlinear Seismic Response of Reinforced Concrete Pedestals In Elevated Water Tanks. 